\title{
Logistics Management and Reform
}

\author{
Jian-Hua ZHANG ${ }^{1, a}$, Yi-Jing XU ${ }^{2, b}$, Zhe ZHANG ${ }^{3, c}$ \\ ${ }^{1}$ General Education Center, Beijing Normal University Zhuhai Campus, China \\ ${ }^{2}$ General Education Center, Beijing Normal University Zhuhai Campus, China \\ ${ }^{3}$ Shenyang Wen Ze Cultural Information Ltd., Shenyang Tiexi Dist., Xinghuanan Street, No.5, China \\ azhuhaijianhua@aliyun.com, b845443202@qq.com, cengel2002@msn.com
}

Keywords: Logistics, Logistics management, Management reform.

\begin{abstract}
China logistics industry fifteen years has made great progress, but still there is a big problem. The author pointed out, in the current domestic market economy environment, how to reform the management of logistics industry, integrate operating behavior of all industries, to mobilize all positive factors to industry bigger and stronger. The author also put forward, the introduction of advanced management concepts and must pay attention to the latest scientific research results, so that small and medium-sized enterprises to get rid of the lower running state. At the last of this performance improvement of the whole industry and to provide users with better and more efficient services, make Chinese logistics industry into the development stage of higher level. These insights have one's own knack in the.
\end{abstract}

\section{Logistics Management Concept}

Logistics management refers to the process of social production, according to the laws of flow of material entities, the basic principle and the application of scientific method of management, planning, organization, command, coordination, control and supervision of the logistics activities, so that all logistics activities to achieve optimal coordination and cooperation, in order to reduce logistics costs, improve logistics efficiency and economic benefit. Modern logistics management is based on system theory, information theory and control theory based on. Previously, the purpose of logistics management is to achieve the level of customer service at the lowest cost possible, a dynamic balance is to seek advantages and cost advantages, and thus create competitive enterprises in the strategic advantage. According to this goal, logistics management to solve the basic problem, simply put, is to the right products to fit the number and the right price at the right time and the right place to provide customers.

"Management" is to emphasize the application of system approach to solve the problem. "Modern logistics" is usually considered by the transport, storage, packaging, handling, distribution processing, distribution and information of the link. Each link that has its own functions, interests and ideas, "System" is the use of modern management methods and modern technology, so that all aspects of information sharing in general, all the links as an integrated system of organization and management, so that the system can cost as low as possible, provide competitive customer service. System method, system efficiency is not their respective local link benefit simple addition. System means that, for a certain aspect of the problem, to analyze and evaluate all of the factors affecting the. Based on this viewpoint, the logistics system is not simply the pursuit of their respective minimum cost in all aspects, because of the tendency of mutual influence, mutual restriction between each link of the logistics efficiency, there are alternating delicate relationship.

\section{The Present Situation of China Logistics}

Modern logistics is the product of economic globalization, economic globalization is an important service. The world of modern logistics industry grows steadily, Europe, Japan, America become important base logistics worldwide. China logistics industry started relatively late, with the rapid development of the national economy, in recent years, China logistics industry to maintain rapid growth, rapid development of the logistics industry, on the one hand to ensure the coordination of the national 
economy, stable, rapid development plays a foundation and support effect, on the other hand, also be to adjust the industrial structure, change the mode of economic development, the important means to develop new economic growth point.

In 2013, China's logistics industry is still in the running in steady growth interval. But the industry market is very clear differentiation. From different industries: FMCG, food, medicine, household appliances, electronics, automotive and consumer related logistics market to maintain a high growth. As the expansion of domestic demand, especially online shopping demand and drive, express, distribution logistics market to maintain rapid growth. The national scale above express business volume totaled 9190000000, grow 61.6\% compared to the same period. But due to the sluggish demand, the domestic economic slowdown, China shipping, air cargo market is still in the doldrums, many large enterprises has loss.

But from an overall perspective, China logistics Learn leader referred to: social logistics cost situation still higher did not change. Economic Daily (reporter Kang Shu reported in Beijing in November 12, 2013): Vice Minister of Commerce, Jiang Zengwei in today's national trade and logistics work conference said, China's logistics cost is high, efficiency is low, can not meet the needs of the development of circulation industry innovation.

\section{The Realization of Goal}

In general, adhere to the principle of rationalization of logistics, is on the premise of cost and service, improve the composing elements of logistics system, to achieve the overall optimization of logistics system.

At the macro level, in addition to improving the support elements outside the building, also need the government and relevant professional organizations planning and guidance.

At the micro level, in addition to the overall optimal management objectives to achieve supply chain, professional and value-added service is important. The eternal theme of modern logistics management is the cost and service, which are trying to cut the cost of logistics, to improve logistics value-added service.

In the service of logistics management, to provide appropriate services include the following aspects, the right quality, the right quantity, the right place, the right impression, the right price, and the right commodity.

\section{Chinese Logistics Industry Reform Direction}

Logistics industry and manufacturing industry, circulation industry, financial industry and other industry linkage to further deepen.

The breadth and depth of logistics network should be extended to urban and rural residents and communities.

Cloud computing, Internet, mobile Internet, intelligent logistics information technology, it brings great changes and new challenges to the logistics industry. We should transform the traditional logistics enterprises on the Internet thinking, accelerate the construction of enterprise logistics information system. Play a central logistics enterprise integration capabilities, through the logistics information chain, to achieve full transparent visual management. Encourage the cooperation of logistics information platform of regional and industry, and to promote the logistics information sharing.

The development potential of the capital market on the logistics industry is very interested in. In 2013, much home industry fund investment are express service, cold chain logistics, logistics, real estate and other fields of chemical. The development of "mixed economy" is an important mode we can choose. In the current domestic market economy environment, how to reform the management of logistics industry, to mobilize all positive factors, the gradual integration of operation behavior of the industry as a whole, logistics industry can become bigger and stronger.

This can to reduce logistics costs, improve logistics efficiency, this logistics mode is to take of promote the transformation and s upgrading of the logistics industry, but also an important means of changing the mode of economic development. 


\section{Summary}

According the spirit of the Third Plenary Session of the eighteen party, 2014 is the first year of implementation of comprehensive reform. We believe that, through unremitting efforts, China logistics industry will be developed rapidly, and entered the ranks of advanced countries.

\section{References}

[1] Liu Ruibai, Chinese logistics industry research and prospect analysis report for 2013 to 2017, Forward-looking Information, 2013.

[2] "2012-2016 China logistics market operation pattern and investment outlook consulting report", http://www.askci.com/reports/201209/08101454167905.shtml.

[3] "In 2013 China eight supply chain innovation case", http://www.itmarket.com.cn/ec/1557.html.

[4] "Our logistics costs accounted for 18\% of GDP close to the developed countries doubled", http://finance.sina.com.cn/chanjing/cyxw/20130814/092016442510.shtml.

[5] Jianhua Zhang, Zhe Zhang, Zhen Ge, General Education and Internet, Advances in Education Research/ Volume 22/ p.68 .

[6] Zhe Zhang, Jianhua Zhang, Zhen Ge, Comparison of Chinese and German Higher Education, Advances in Education Research/ Volume 22/ p.81.

[7] Jianhua Zhang, Zhen Ge, General Education and Practice in University, Advances in Education Research/Volume 4/ p.158. 